\title{
Assessment of seasonal variation on neonatal sepsis
}

\author{
Mohamed A. Abdel Mawla, Eman A. Mostafa, Rasha M. Hasanin* ${ }^{*}$ and Mohab M. Salah
}

\begin{abstract}
Background: Neonatal sepsis is the major cause of morbidity and mortality in neonates. Frequency of bacterial sepsis is affected by seasonal variations. This study was done to rule out the effects of seasonal variation on neonatal sepsis and to determine isolated bacterial agents and their antibiotic sensitivity profile.

Results: This cross-sectional study included 100 neonates with suspected sepsis, and conducted during summer and winter seasons. High frequencies of neonatal morbidities were observed like poor feeding (98\%), Jaundice (82\%), pallor (76\%), respiratory distress (66\%) and convulsions (64\%) in winter, whereas fever (40\%) and edema (12\%) in summer. Statically significant correlation was found between the seasonal variations and different symptomatic expression of bacteremia like jaundice, respiratory distress, convulsions and poor feeding ( $p$ value $<0.001$ ) in winter, while pallor, fever and edema ( $p$ value $<0.05$ ) in summer. Our study showed high proportion of neonatal infection with Gram negative bacteria, as (40\%) Pseudomonas aeruginosa and (16\%) Escherichia coli in winter season, while (22\%) Enterobacter in summer. Carbapenems was very effective against Pseudomonas aeruginosa isolates, Klebsiella pneumonia, Enterobacter, Acinetobacter, Escherichia coli, Staphylococcus aureus and Listeria, while theses bacterial isolates showed (80-100\%) resistance to Unasyn and Cephalosporins (3rd generation).

Conclusion: This study showed that Seasonal variations had effects on neonatal sepsis regarding their both different symptomatic expressions and bacterial isolates. Most of isolates were sensitive to Carbapenems and resistant to both Unasyn and Cephalosporins (3rd generation).
\end{abstract}

Keywords: Seasonal variation, Neonatal sepsis, Morbidity, Bacteremia

\section{Background}

Neonatal sepsis is the major cause of morbidity and mortality in neonates (Mohammad et al. 2014). Worldwide, about 2.8 million neonatal deaths occurred in 2013 (Liu et al. 2015). Among the under 5 year-old children deaths, neonatal mortality rate raised from 37 to $42 \%$ in period from 2000 to 2013 (Kassebaum et al.2014). Almost all of these deaths usually occur in low socioeconomic countries and about one million of these deaths are due to infections like neonatal sepsis, pneumonia and meningitis (Black et al. 2010). On contrary, the survivors of

*Correspondence: rashamahmoud97@yahoo.com Department of Pediatrics, National Research Centre (NRC), El Buhouth St., Dokki, P.O. 12622, Cairo, Egypt neonatal sepsis usually suffer from short- and long-term neurodevelopmental abnormalities (Ferreira et al. 2014).

Developing countries like Egypt represent the majority of reported neonatal deaths, globally (Rabie et al. 2015). For example, rate of sepsis in neonatal intensive care units in Tanta (2019) was 43.94\% during the study period (Shimaa et al. 2019). Another study performed in South Sinai hospitals (2016) declared that incidence of neonatal sepsis was about $8.6 \%$ during the study period due to the abundance of risk factors in this area (Medhat and El Kalioby 2017).

Neonatal sepsis is a clinical syndrome manifested by symptoms, signs of infection and bacterial pathogen isolation from the bloodstream in an infant 28 days of life or younger (Edwards and Baker 2004, Shimaa et al. 2019).

\section{Springer Open}

(c) The Author(s) 2021. Open Access This article is licensed under a Creative Commons Attribution 4.0 International License, which permits use, sharing, adaptation, distribution and reproduction in any medium or format, as long as you give appropriate credit to the original author(s) and the source, provide a link to the Creative Commons licence, and indicate if changes were made. The images or other third party material in this article are included in the article's Creative Commons licence, unless indicated otherwise in a credit line to the material. If material is not included in the article's Creative Commons licence and your intended use is not permitted by statutory regulation or exceeds the permitted use, you will need to obtain permission directly from the copyright holder. To view a copy of this licence, visit http://creativecommons.org/licenses/by/4.0/. 
Major risk factors for neonatal sepsis in low-income countries are due to maternal causes as bad environmental hygiene, delivering the babies at home and lack of medical services. In addition to these factors, seasonal variation of the year can affect the rate of neonatal morbidity and are mostly related to maternal health and the postnatal conditions (Donald et al. 2011).

Frequency of other neonatal morbidities as fever, diarrhea, sepsis, breast feeding problems, asphyxia, upper respiratory infections, skin and umbilical infections which are affected by seasonal variation have not been evaluated satisfactorily till now (ARIF et al. 2019). Maternal intra-partum fever, birth and admission season, mode of delivery and preterm gestational age have increased the incidence of neonatal sepsis (Temsegen et al. 2019).

Diagnosis and management of sepsis are a great challenge facing neonatologists in NICUs. Clinical diagnosis at presentation is difficult due to nonspecific signs and symptoms. In addition, laboratory diagnosis is time consuming (Rabie et al. 2015).

Neonatal sepsis is caused by Gram-positive and Gramnegative bacteria and Candida (Jumah and Hassan 2007). The diversity of organisms causing sepsis varies from region to another and changes over time even in the same place (Zea and Ochoa 2015). This is attributed to the changing pattern of antibiotic use and changes in lifestyle (Ghotaslou et al. 2007). Environmental changes may be a possible factor for causing neonatal infections as neonates have a weak immunity and can't tolerate the difficult conditions, so seasonal variations are known to affect the prevalence of neonatal infection (Omoregie et al. 2009).

For this reason, the aim of this study was to find out the effect of seasonal changes on neonatal sepsis and characterized the microbiological pattern of it in each season and their antibiotic sensitivity profile.

\section{Methods}

One hundred neonates with age ranging from 0 day to 28 days were recruited from neonatal intensive care unit in Nasser general hospital, 50 neonates during summer season (from April to September) and 50 during winter season (from October to March). Neonates with clinical signs and symptoms of septicemia were enrolled in this study. Neonates already treated with antibiotics were excluded.

All newborns were subjected to the following: full maternal history taking, detailed antenatal and perinatal history, clinical examination including: 1-Gestational age assessment; 2-Modified Ballard scoring system (Bizzarro et al. 2008); 3-Apgar score estimation at 1 and 5 min to assess the presence of perinatal asphyxia (Garner et al. 1988); 4-vital signs: Pulse; Temperature; RR;
5-Anthropometric measures: weight, length and head circumference; 6-Full cardiac, chest, abdominal and neurological examination; 7-Risk factors for sepsis: premature rupture of membranes (PROM), maternal fever, insertion of an umbilical catheter.

According to the Egyptian Neonatal Network (EGNN), sepsis is defined as presence of at least 3 out of the following four criteria (EGNN 2010): presence of risk factors of sepsis (e.g., prematurity, chorioamnionitis), presence of two or more clinical signs of sepsis (poor reflexes, lethargy, respiratory distress, bradycardia, apnea, convulsions, abdominal distension, and bleeding), abnormal hemogram and positive CRP and positive culture.

\section{Laboratory investigations}

Blood samples were collected from the neonates with suspected sepsis for CBC, CRP, and blood cultures. Blood was collected from a peripheral vein. Approximately, $1 \mathrm{~mL}$ of blood was inoculated directly into blood culture medium vials and sent to our clinical microbiology laboratory for cultivation and subsequent processing.

The blood culture bottles were incubated aerobically and anaerobically at $37^{\circ} \mathrm{C}$ for 24 hours and subcultures on MacConkey agar, blood agar, and chocolate agar and examined for growth after 24-48 h. The same protocol was repeated daily for 7 days before blood culture was considered to be free of microorganisms (to be negative blood culture). Organisms were identified by Gram staining and biochemical reactions. The antimicrobial susceptibility testing was done by Kirby-Bauer disc diffusion method on Mueller-Hinton agar.

\section{Statistical analysis}

The standard computer program Statistical Package for the Social Sciences (SPSS) for Windows, release 19.0 (SPSS Inc., USA) was used for data entry and analysis. All numeric variables were expressed as mean \pm standard deviation (SD), and percentage when appropriate. For all tests, a probability $(p)$ less than 0.05 were considered significant.

\section{Results}

This was a cross-sectional study that included 100 neonates admitted at Naser general hospital during 2018 due to different causes half of them were during summer months from April to September and the other half were during winter months from October to March,

Table 1 shows significant difference regarding gestational age, weight, length and head circumference between summer and winter cases. There was significant decrease in hemoglobin (HG) and platelet count (PLT), total leukocytic count (TLC) in winter cases when compared to summer cases. 
Table 1 The descriptive, demographic and laboratory data of cases

\begin{tabular}{lllc}
\hline & $\begin{array}{l}\text { Summer cases } \\
\text { Mean } \pm \text { SD }\end{array}$ & $\begin{array}{l}\text { Winter cases } \\
\text { Mean } \pm \text { SD }\end{array}$ & $P$ value \\
\hline Gestational age (weeks) & $30.18 \pm 2.488$ & $35 \pm 2.01$ & $<0.001$ \\
Weight $(\mathrm{kg})$ & $1.2 \pm 0.39$ & $2.9 \pm 0.17$ & $<0.001$ \\
Length $(\mathrm{cm})$ & $38 \pm 3.11$ & $42.8 \pm 2.3$ & $<0.001$ \\
HC $(\mathrm{cm})$ & $30 \pm 2.1$ & $27 \pm 1.8$ & $<0.001$ \\
Pulse $($ beat/min) & $140.8 \pm 14.7$ & $144 \pm 14.78$ & 0.15 \\
Temperature $\left({ }^{\circ} \mathrm{C}\right)$ & $37.9 \pm 3.8$ & $39.1 \pm 5.1$ & 0.01 \\
RR $($ breath/min) & $35 \pm 3$ & $44 \pm 3.6$ & $<0.001$ \\
HB $(\mathrm{gm} / \mathrm{dl})$ & $12.2 \pm 2.12$ & $7.7 \pm 1.6$ & $<0.001$ \\
PLT $\left(10^{3} / \mathrm{ul}\right)$ & $162 \pm 104$ & $78 \pm 23$ & $<0.001$ \\
TLC $\left(10^{3} / \mathrm{ul}\right)$ & $18.3 \pm 9.22$ & $4.3 \pm 2.45$ & $<0.001$ \\
Staff/segmented & $0.21 \pm 1.06$ & $0.49 \pm 1.9$ & 0.37 \\
CRP $(\mathrm{mg} / \mathrm{dl})$ & $36 \pm 15.3$ & $85 \pm 61.4$ & $<0.001$ \\
Total bilirubin $(\mathrm{mg} / \mathrm{dl})$ & $15.8 \pm 3.7$ & $20.5 \pm 4.6$ & $<0.001$ \\
Direct bilirubin $(\mathrm{mg} / \mathrm{dl})$ & $1.5 \pm 0.8$ & $1.9 \pm 0.91$ & 0.02 \\
TORCH & $5 / 50$ & $4 / 50$ & 0.3 \\
\hline
\end{tabular}

Data expressed as means \pm standard deviation $p$-values $<0.05$ is significant

Table 2 Descriptive study of cases regarding the mode of delivery

\begin{tabular}{llll}
\hline & NVD & CS & $\boldsymbol{p}$ value \\
\hline Summer cases $N=50$ & $18 / 50$ & $32 / 50$ & 0.06 \\
Winter cases $N=50$ & $13 / 50$ & $37 / 50$ & 0.007 \\
\hline
\end{tabular}

$p$ values $<0.05$ is significant, Normal vaginal delivery (NVD), Cesarean section (CS), $N=$ number

There was significant increase in the CRP marker and neonatal core temperature in winter cases when compared to summer cases as seen in Table 1.

Head circumference (HC), Respiratory rate (RR), hemoglobin (HB), platelet count (PLT), total leukocytic count (TLC), $\mathrm{C}$ reactive protein (CRP), TORCH $=$ Toxoplasma, Rubella, Cytomegalo virus, Herpes virus.

There was significant increase in the number of cases delivered by cesarean section in winter as seen in Table 2 .

While comparing the maternal conditions there was significant increase in the number of cases developed premature rupture of membrane (PROM) and maternal urinary tract infection (UTI) in summer than winter as seen in Table 3.

Regarding symptoms and signs there were significant increase in number of cases admitted with neonatal jaundice, respiratory distress, convulsions, poor feeding, skin manifestations in winter cases while pallor, edema and fever in summer cases (Table 4).

While analyzing the results of cultures done during period of admission in both groups there was
Table 3 Comparison of maternal conditions of the cases

\begin{tabular}{lllr}
\hline & Summer cases & Winter cases & $\boldsymbol{P}$ value \\
& $\boldsymbol{N}=\mathbf{5 0}$ & $\boldsymbol{N}=\mathbf{5 0}$ & \\
\hline PROM & $32 / 50$ & $13 / 50$ & 0.0001 \\
Fever & $9 / 50$ & $15 / 50$ & 0.16 \\
UTI & $46 / 50$ & $26 / 50$ & $<0.001$ \\
\hline
\end{tabular}

$p$ values $<0.05$ is significant, premature rupture of membrane (PROM), urinary tract infection(UT), $N=$ number

Table 4 Comparison between symptoms and signs of cases

\begin{tabular}{lrrc}
\hline & \multicolumn{1}{l}{$\begin{array}{l}\text { Summer cases } \\
\boldsymbol{N}(\%)\end{array}$} & \multicolumn{1}{l}{$\begin{array}{l}\text { Winter cases } \\
\boldsymbol{N}(\%)\end{array}$} & $\boldsymbol{P}$ value \\
& $24 / 50=48 \%$ & $38 / 50=76 \%$ & 0.003 \\
\hline Pallor & $26 / 50=52 \%$ & $30 / 50=60 \%$ & 0.4 \\
Cyanosis & $6 / 50=12 \%$ & $1 / 50=2 \%$ & 0.04 \\
Edema & $10 / 50=20 \%$ & $41 / 50=82 \%$ & $<0.001$ \\
Jaundice & $11 / 50=22 \%$ & $33 / 50=66 \%$ & $<0.001$ \\
Respiratory distress & $19 / 50=38 \%$ & $28 / 50=56 \%$ & 0.07 \\
Cardiac symptoms & $9 / 50=18 \%$ & $11 / 50=22 \%$ & 0.5 \\
Organomegaly & $41 / 50=82 \%$ & $37 / 50=74 \%$ & 0.3 \\
Abdominal distension & $13 / 50=26 \%$ & $32 / 50=64 \%$ & $<0.001$ \\
Convulsions & $20 / 50=40 \%$ & $49 / 50=98 \%$ & $<0.001$ \\
Poor feeding & $20 / 50=40 \%$ & $3 / 50=6 \%$ & $<0.001$ \\
Fever & $44 / 50=88 \%$ & $48 / 50=96 \%$ & 0.14 \\
Lethargy & $17 / 50=34 \%$ & $37 / 50=74 \%$ & $<0.001$ \\
Skin signs & $16 / 50=32 \%$ & $22 / 50=44 \%$ & 0.2 \\
Poor perfusion & $11 / 50=22 \%$ & $18 / 50=36 \%$ & 0.12 \\
Diarrhea & $7 / 50=14 \%$ & $4 / 50=8 \%$ & 0.33 \\
TORCH & &
\end{tabular}

TORCH = Toxoplasma, Rubella, Cytomegalo virus, Herpes virus. $N=$ number

Table 5 Comparison between both seasons regarding bacterial isolates from the blood culture

\begin{tabular}{lccl}
\hline Organism & Summer $(\boldsymbol{N = 5 0} \%$ & Winter $(\boldsymbol{N}=\mathbf{5 0}) \%$ & $\boldsymbol{p}$ value \\
\hline Klebsiella & $10(20 \%)$ & $8(16 \%)$ & 0.7 \\
Pseudomonas & $7(14 \%)$ & $20(40 \%)$ & 0.001 \\
E. coli & $2(4 \%)$ & $8(16 \%)$ & 0.04 \\
Staph aureus & $10(20 \%)$ & $8(16 \%)$ & 0.7 \\
Listeria & $3(6 \%)$ & $1(2 \%)$ & 0.5 \\
Enterobacter & $11(22 \%)$ & $1(2 \%)$ & 0.007 \\
Acinetobacter & $7(14 \%)$ & $4(8 \%)$ & 0.5 \\
\hline
\end{tabular}

significant increase in number of cases developed pseudomonas and $\mathrm{E}$ coli in winter cases while there was significant increase in number of cases developed Enterobacter in summer cases as seen in Table 5 and Fig. 1. 


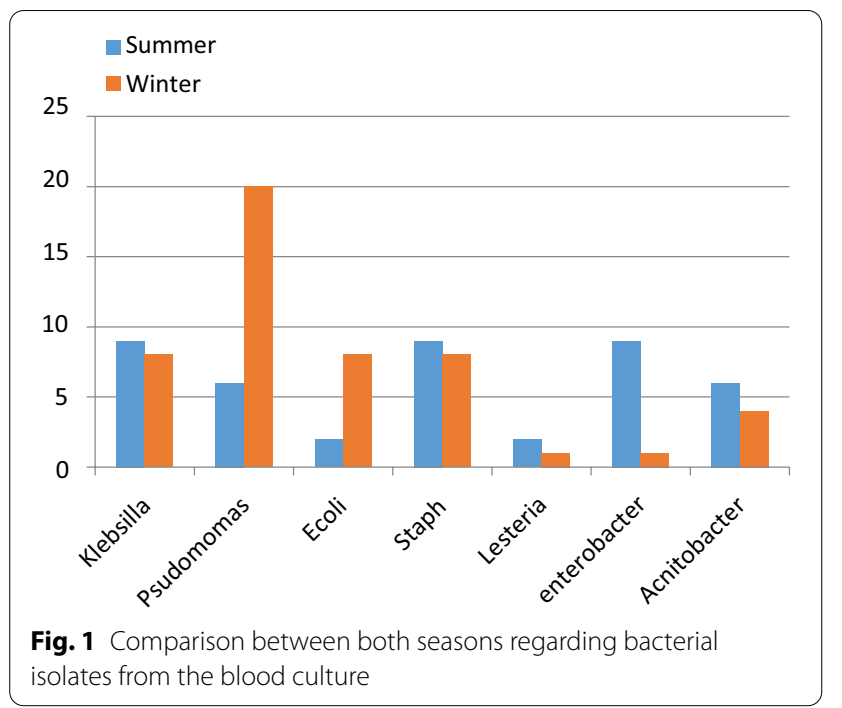

Table 6 shows that Carbapenems was very effective against Gram positive and Gram negative bacteria. Also Cephalosporins (4th generation: Maxipime) was effective in treatment of Gram negative bacteria. Staphylococcus and Listeria isolates demonstrated significant sensitivity to Vancomycin which was $83.3 \%$ and $100 \%$, respectively. Enterobacter, E. coli and Listeria isolates showed highly sensitivity to Azithromycin. Gram positive and negative bacteria showed $(80-100 \%)$ resistance to Unasyn and Cephalosporins (3rd generation: Ceftazidime).

\section{Discussion}

Neonatal sepsis is life-threatening condition for neonates in developing countries and if any delay in the treatment occurred it may become fatal. Proper treatment requires knowledge of common bacterial organisms involved and the most prevalent risk factors (Thapa and Sapkota 2019).

We found significant increase in gestational age, weight and length between winter cases this agree with (McGrath et al. 2006) who said those born in winter tend to have higher anthropometric indices that may persist into adulthood due to a gradual decrease in body measurements during subsequent seasons with the least growth rate in the winter (Elżbieta et al. 2008). This may refer to alteration in vitamin D synthesis, seasonal differences in light exposure, and seasonal change in maternal diet during pregnancy (Watson and McDonald 2007).

Our study illustrated significant increase in cases delivered by CS in winter and it may be associated with the risk of neonatal sepsis development this agree with results of (Moges et al. 2017; Utomo 2016) and disagree with Siakwa et al. 2014. Because newborns delivered by CS are more liable to laceration due to usage of sharp instruments during procedure (Adatara et al. 2018), also they are not exposed to vaginal bacteria, they experience delayed initiation of breastfeeding which may deny the neonate from the protective effect of colostrum against microbes and prolonged hospital stay (Adatara et al. 2019).

We found significant increase in cases developed PROM and maternal UTI in summer than winter ( $p$ value $<0.001)$ this correlate with the result of Yackerson

Table 6 Antibiotic sensitivity profile of bacterial isolates

\begin{tabular}{|c|c|c|c|c|c|c|c|c|}
\hline \multirow[t]{3}{*}{ Isolate } & \multicolumn{8}{|c|}{ Antibacterial agent } \\
\hline & \multicolumn{2}{|l|}{ Carbapenems } & \multicolumn{2}{|c|}{ Cephalosporins } & \multirow{2}{*}{$\begin{array}{l}\text { Macro-lides } \\
\text { Azithromycin }\end{array}$} & \multirow{2}{*}{$\begin{array}{l}\text { Glyco- } \\
\text { peptides } \\
\text { Vancomycin }\end{array}$} & \multirow{2}{*}{$\begin{array}{l}\text { Aminoglycosides } \\
\text { Amikacin }\end{array}$} & \multirow{2}{*}{$\begin{array}{l}\text { Ampicillin- } \\
\text { sulbactam } \\
\text { Unasyn }\end{array}$} \\
\hline & Imi-penem & Mero-penem & $\begin{array}{l}\text { Maxipime } \\
\text { (4th) }\end{array}$ & $\begin{array}{l}\text { Ceftazidime } \\
\text { (3rd) }\end{array}$ & & & & \\
\hline $\begin{array}{l}\text { Pseudo- } \\
\text { monas } \\
N=27\end{array}$ & $22=81.5 \%(S)$ & $19=70.4 \%(S)$ & NT & $22=81.4 \%(R)$ & $\mathrm{NT}$ & NT & $17=63 \%(S)$ & NT \\
\hline $\begin{array}{c}\text { Kleb-siella } \\
N=18\end{array}$ & $18=100 \%(S)$ & $11=61 \%(S)$ & $15=83.3 \%(S)$ & $7=38.9 \%(R)$ & $11=61 \%(S)$ & NT & NT & $18=100 \%(R)$ \\
\hline $\begin{array}{l}\text { Entero-bacter } \\
\qquad N=12\end{array}$ & $12=100 \%(S)$ & $12=100 \%(I)$ & $12=100 \%(S)$ & $12=100 \%(R)$ & $10=83.8 \%(S)$ & NT & $12=100 \%(I)$ & $3=25 \%(R)$ \\
\hline $\begin{array}{l}\text { Acineto-bac- } \\
\text { ter } N=11\end{array}$ & $7=63.6 \%(S)$ & $9=81.8 \%(I)$ & $7=63.6 \%(S)$ & $3=27.3 \%(R)$ & $7=63.6 \%(S)$ & NT & NT & $9=81.8 \%(R)$ \\
\hline E. coli $N=10$ & $10=100 \%(S)$ & NT & $10=100 \%(S)$ & NT & $10=100 \%(S)$ & $5=50 \%(I)$ & NT & $10=100 \%(R)$ \\
\hline $\begin{array}{l}\text { Staph. aureus } \\
\qquad N=18\end{array}$ & $16=88.8 \%(S)$ & $11=61.1 \%(S)$ & NT & $15=83.3 \%(R)$ & NT & $15=83.3 \%(\mathrm{~S})$ & $15=83.3(\mathrm{~S})$ & NT \\
\hline Listeria $N=4$ & $4=100 \%(S)$ & $3=75 \%(S)$ & NT & NT & $3=75 \%(S)$ & $4=100 \%(S)$ & NT & $4=100 \%(R)$ \\
\hline
\end{tabular}

(S)sensitive/(I)intermediate sensitivity/(R)resistant/NS: not tested 
et al. 2008. Intra-partum maternal fever increased the incidence of neonatal sepsis by 9 times as shown in the study of (Temsegen et al. 2019). This correlated with previously done studies as in Mekelle city, Ethiopia (Gebremedhin et al. 2016), Karachi, Pakistan (Alam et al. 2014) and in Bangladesh (Hasan and Mahmood 2011). These Studies suggested maternal infections due to intra-partum fever. As maternal infection transmitted frequently to the baby as ascending, during passage through the birth canal or via circulation and it causes early-onset sepsis (Hasan and Mahmood 2011). In present study, higher number of suspected neonatal sepsis cases was observed in winter than in summer ( $p$ value $<0.001)$. These results are similar to other studies done in Pakistan and Nigeria, where bacterial blood infection in neonates were also high in the winter represented by $(57.4 \%$ ) in Pakistan (ARIF et al. 2019) and (28.4\%) in Nigeria (Omoregie et al. 2009). Another study in America showed that seasonal variation can affect the sepsis epidemiology, as frequency and death rate which was increased in winter season. Increased prevalence of sepsis in winter might be due to weak immunity of neonates in this season (Danai et al. 2007). On the other hand, a study in Canada identified a significant increase in neonatal sepsis during the summer months (Shah et al. 2013). The reason for seasonal variation in neonatal sepsis is unclear, but may be due to humidity with high temperature of such season which create a suitable environment for bacterial growth (Temsegen et al. 2019). We observed high frequencies of neonatal morbidities during winter season like poor feeding (98\%), Jaundice (82\%), pallor (76\%), skin manifestations (74\%), respiratory distress (66\%) and convulsions (64\%) which showed statically significant correlation ( $p$ value $<0.001$ ), whereas pallor (48\%), fever $(40 \%)$ and edema $(12 \%)$ in summer ( $p$ value $<0.05$ ). Our result is in concordance with two previous studies showed significant relationship among different morbidities and seasonal variations done in Pakistan and India (ARIF et al. 2019).

In our study, 20\% Gram positive bacteria and $80 \%$ Gram negatives were responsible for neonatal bacteremia. Different studies showed similar results (Alam et al. 2014; Hasan and Mahmood 2011; ARIF et al. 2019). Here, $80 \%$ of the main isolates were Gram negative organisms which quite similar to Kumhar et al. (2002).

We demonstrated that among gram negatives, Pseudomonas aeruginosa and E. coli were the leading cause of bacteremia in winter season, while Enterobacter in summer. ARIF et al. (2019) revealed that $P$. aeruginosa and Staphylococcus epidermidis were the main cause of neonatal bacteremia in winter and Eber et al. (2011) showed that Staphylococcus aureus and K. pneumonia were the main bacterial isolates from blood in winter season infection. While Al-Hasan et al. (2009) found that $E$. coli was the main cause for bacterial blood infection in summers.

Pseudomonas aeruginosa pathogen is involved mostly in hospital acquired infection which might be responsible for neonatal bacteremia. High flow of patients with attendants in winters due to different diseases and poor hygiene conditions of hospitals are responsible for these infections (ARIF et al. 2019).

Our study results showed that $P$. aeruginosa isolates were $81.5 \%$ sensitive, K. pneumonia 100\%, Enterobacter $100 \%$, Acinetobacter $63.6 \%$, E. coli 100\%, Staphylococcus aureus $88.8 \%$ and Listeria $100 \%$ to Carbapenems, also ARIF et al. (2019) showed that Staphylococcus aureus were $80 \%$ sensitive, K. pneumonia $100 \%$, P. aeruginosa 80\% and Escherichia coli $70-80 \%$ to Carbapenems. Staphylococcus and Listeria isolates demonstrated significant sensitivity to Vancomycin which was $83.3 \%$ and $100 \%$, respectively, while Tsering et al. (2011) showed that Staphylococcus was $40 \%$ sensitive to Vancomycin. Most of bacterial isolates in our study showed $80-100 \%$ resistance to Unasyn and Cephalosporins (3rd generation) this was quite similar to results of Muhammed et al. (2010). This drug resistance may be due to their use as blind therapy in emergencies and surgery.

\section{Conclusion}

This study showed that Seasonal variations had effects on neonatal sepsis regarding their both different symptomatic expressions and bacterial isolates. High proportion of neonatal infection was caused by Gram negative bacteria. According to antibiotic sensitivity Carbapenems were very effective against most of bacterial isolates, while Unasyn and Cephalosporins (3rd generation) were $80-100 \%$ resistance against them.

\section{Abbreviations \\ HC: Head circumference; RR: Respiratory rate; HB: Hemoglobin; PLT: Platelet count; TLC: Total leukocytic count; CRP: C reactive protein; TORCH: Toxoplasma, Rubella, Cytomegalo virus, Herpes virus; NVD: Normal vaginal delivery; CS: Cesarean section; PROM: Premature rupture of membrane; UTI: Urinary tract infection; N: Number; S: Sensitive; I: Intermediate sensitivity; R: Resistant; NS: Not tested; EGNN: Egyptian Neonatal Network.}

\section{Acknowledgements}

The authors are grateful to the Center of Excellence for Medical Research at National Research Centre-Egypt, and we would like to thank the patients and their parents.

\section{Authors' contributions}

AM contributed to the interpretation, and analysis of data. EA contributed to the writing the manuscript. RM revised and approved the final manuscript, and is the corresponding author. MS contributed to the idea (concept) of the study, and study design, and the collection of cases. All authors have read and approved the final manuscript.

\section{Funding}

This study did not receive any financial support. 


\section{Availability of data and materials}

The datasets generated during this study are available from the Corresponding author on reasonable request.

\section{Ethics approval and consent to participate}

Written consent was obtained from the parents, and the study protocol was approved by the National Research Centre Ethics Committee (No. 19007).

\section{Consent for publication}

Not applicable.

\section{Competing interests}

The authors declare that they have no competing interests.

Received: 19 May 2020 Accepted: 10 January 2021

Published online: 21 January 2021

\section{References}

Adatara P, Afaya A, Salia SM, Afaya RA et al (2018) Risk factors for neonatal sepsis: a retrospective case-control study among neonates who were delivered by caesarean section at the Trauma and Specialist Hospital, Winneba. Ghana Biomed Res Int 2018:6153501. https://doi. org/10.1155/2018/6153501

Adatara P, Afaya A, Salia SM, Afaya RA, Konlan KD, Agyabeng-Fandoh E et al (2019) Risk factors associated with neonatal sepsis: a case study at a specialist hospital in Ghana. Sci World J 2019:9369051

Alam MM, Saleem AF, Shaikh AS, Munir O, Qadir M (2014) Neonatal sepsis following prolonged rupture of membranes in a tertiary care hospital in Karachi, Pakistan. J Infect Dev Ctries 8(01):067-073

Al-Hasan M, Lahr B, Eckel-Passow JE, Baddour L (2009) Seasonal variation in Escherichia coli bloodstream infection: a population-based study. Clin Microbiol Infect 15:947-950

Arif A, Hasan F, Khan QA et al (2019) Affect of seasonal variation on bacterial sepsis and antibiotic sensitivity profile in neonates. Pak Pediatr J 43(4):247-254

Bakry MMEL, Sherbini MTEL, Ahmady MMEL, El Ghoroury EA, Ahmad AM, Elshamaa MF, Salah MM (2014) Diagnostic value of soluble E-selectin and highly sensitive C-reactive protein as markers for neonatal sepsis. Med Res J 13:74-79

Bizzarro MJ, Dembry L-M, Baltimore RS, Gallagher PG (2008) Changing patterns in neonatal Escherichia coli sepsis and ampicillin resistance in the era of intrapartum antibiotic prophylaxis. Pediatrics 121(4):689-696

Black RE, Cousens S, Johnson HL et al (2010) Global, regional, and national causes of child mortality in 2008: a systematic analysis. Lancet 375(9730):1969-1987

Danai PA, Sinha S, Moss M, Haber MJ, Martin GS (2007) Seasonal variation in the epidemiology of sepsis. Crit Care Med 35:410-415. https://doi. org/10.1016/j.jped.2013.09.006

Eber MR, Shardell M, Schweizer ML, Laxminarayan R, Perencevich EN (2011) Seasonal and temperature-associated increases in gram-negative bacterial bloodstream infections among hospitalized patients. PLoS ONE 6:e25298

Edwards MS, Baker CJ (2004) Sepsis in the newborn. Krugman's Infectious Diseases of Children. Philadelphia: Mosby, pp 545-561

Egyptian Neonatal Network (EGNN) (2010)

El-Mashad SM, Hamam SM, El-Farargy MS, El-Sharkawy HM (2019) Incidence of neonatal sepsis and the causative organisms in neonatal intensive care unit of Tanta University Hospital. A study from Egypt. Med J Cairo Univ 87(8):5323-5332

Ferreira RC, Mello RR, Silva KS (2014) Neonatal sepsis as a risk factor for neurodevelopmental changes in preterm infants with very low birth weight. J Pediat 90(3):293-299

Garner JS, Jarvis WR, Emori TG, Horan TC, Hughes JM (1988) CDC definitions for nosocomial infections, 1988. Am J Infect Control 16(3):128-140. https:// doi.org/10.1016/0196-6553(88)90053-3

Gebremedhin D, Berhe H, Gebrekirstos K (2016) Risk factors for neonatal sepsis in public hospitals of Mekelle City, North Ethiopia, 2015: unmatched case control study. PLOS ONE 11(5):e0154798

Ghotaslou R, Ghorashi Z, Nahaei M-R (2007) Klebsiella pneumoniae in neonatal sepsis: a 3-year-study in the pediatric hospital of Tabriz, Iran. Jpn J Infect Dis 60(2-3):126-128
Hasan M, Mahmood C (2011) Predictive values of risk factors in neonatal sepsis. J Bangladesh Coll Phys Surg 29(4):187-195

Jumah DS, Hassan MK (2007) Predictor of mortality outcome in neonatal sepsis. Med J Basrah Univ 25:11-18

Kassebaum NJ, Bertozzi-Villa A, Coggeshall MS, Shackelford KA, Steiner C, Heuton KR et al (2014) Global, regional, and national levels and causes of maternal mortality during 1990-2013: a systematic analysis for the Global Burden of Disease Study 2013. Lancet 384(9947):980-1004

Kumhar GD, Ramachandran V, Gupta P (2002) Bacteriological analysis of blood culture isolates from neonates in a tertiary care hospital in India. J Health Popul Nutr 2002:343-347

Liu L, Oza S, Hogan D, Perin J, Rudan I, Lawn JE et al (2015) Global, regional, and national causes of child mortality in 2000-13, with projections to inform post-2015 priorities: an updated systematic analysis. Lancet 385(9966):430-440

McGrath JJ, Saha S, Lieberman DE, Buka S et al (2006) Season of birth is associated with anthropometric and neurocognitive outcomes during infancy and childhood in a general population birth cohort. Schiz Res 81:91-100

Medhat H, Khashana A, El-Kalioby M (2017) Incidence of Neonatal Infection in South Sinai, Egypt. Int J Infect 4(1):36615. https://doi.org/10.17795/ iji-36615

Moges F, Eshetie S, Yeshitela B, Abate E (2017) Bacterial etiologic agents causing neonatal sepsis and associated risk factors in Gondar, Northwest Ethiopia. BMC Pediatr 17(1):137

Muhammad Z, Ahmed A, Hayat U, Wazir MS, Rafiyatullah WH (2010) Neonatal sepsis: causative bacteria and their resistance to antibiotics. J Ayub Med Coll Abbottabad 22:33-36

Omoregie R, Egbe CA, Ogefere HO, Igbarumah I, Omijie RE (2009) Effects of gender and seasonal variation on the prevalence of bacterial septicemia among young children in Benin City, Nigeria. Libyan J Med 4(3):107-109

Puch EA, Krenz-Niedbała M, Chrzanowska M (2008) Body height differentiation by season of birth: girls from Cracow, Poland. Anthropol Rev 71:3-16

Rabie EM, El-Din S, Adel El-Sokkary MM, Bassiouny MR, Hassan R (2015) Epidemiology of neonatal sepsis and implicated pathogens. Biomed Res Int 2015:11

Shah PS, Yoon W, Kalapesi Z, Bassil K, Dunn M, Lee SK (2013) Seasonal variations in healthcare-associated infection in neonates in Canada. Arch Dis Childhood Fetal Neonatal Ed 98(1):F65-F69

Siakwa M, Kpikpitse D, Mohamed SS (2014) Neonatal sepsis in rural Ghana: a case control study of risk factors in a birth cohort. Int J Res Med Health Sci 4(5):77-88

Temesgen WG, Ejigu GZ, Ayenew ML (2019) The role of the season at admission in neonatal sepsis: a retrospective chart review of a 1-year data at University of Gondar comprehensive specialized hospital Gudayu et al. BMC Res Notes 12:643

Thapa S, Sapkota LB (2019) Changing trend of neonatal septicemia and antibiotic susceptibility pattern of isolates in Nepal. Int J Pediatr 2019:3784529

Tsering DC, Chanchal L, Pal R, Kar S (2011) Bacteriological profile of septicemia and the risk factors in neonates and infants in Sikkim. J Glob Infect Dis 3:42

Utomo MT (2016) Risk factors of neonatal sepsis: a preliminary study in Dr. Soetomo Hospital. Indones J Trop Infect Dis 1(1):23-26

Waters D, Jawad I, Ahmad A et al (2011) Aetiology of community-acquired neonatal sepsis in low and middle income countries. J Glob Health 1(2):154-170

Watson PE, McDonald BW (2007) Seasonal variation of nutrient intake in pregnancy: effects on infant measures and possible influence on diseases related to season of birth. Eur J Clin Nutr 61:1271-1280

Yackerson N, Piura B, Sheiner E (2008) The influence of meteorological factors on the emergence of preterm delivery and preterm premature rupture of membrane. J Perinatol 28:707-711

Zea-Vera A, Ochoa TJ (2015) Challenges in the diagnosis and management of neonatal sepsis. J Trop Pediatr 61(1):1-13w

\section{Publisher's Note}

Springer Nature remains neutral with regard to jurisdictional claims in published maps and institutional affiliations. 